\title{
O DISPOSITIVO JORNALÍSTICO E OS DISCURSOS TRANS: UMA ANÁLISE DA FOLHA DE SÃO PAULO
}

\author{
Atilio BUTTURI JUNIOR ${ }^{1}$ \\ Denise Ayres D’ÁVILA²
}

\begin{abstract}
Resumo: Este trabalho tem como objetivo problematizar a produção dos discursos sobre as pessoas trans veiculados na mídia brasileira, a partir de uma análise que parte dos debates foucaultianos e de algumas das discussões de gênero e do transfeminismo hodiernas. O corpus é composto de textos informativos on-line (publicados entre $1^{\circ}$ de agosto de 2014 e 3 de outubro de 2014), da versão diária do jornal Folha de São Paulo e que versam, de maneiras distintas, sobre aspectos do discurso trans. A hipótese a ser defendida é a de que, não obstante os deslocamentos empreendidos pelos discursos de gênero e pelo transfeminismo, permanecem nos discursos da Folha enunciados de normalização e enunciados de naturalização na produção de textos sobre o acontecimento trans.
\end{abstract}

Palavras-chave: Trans. Dispositivo. Discurso. Mídia. Produção de gênero.

\section{Introdução}

No texto Doing Justice to Someone, Judith Butler (2006) debruça-se sobre os regimes de verdade que produzem os discursos sobre o sexo e o gênero, partindo de um debate médico-jurídico canadense e norte-americano, célebre na década de noventa do século XX. Trata-se do “caso” de John/Joan, que teve o pênis queimado quando tinha poucos meses de idade, durante uma cirurgia, e cujo “destino” foi o das transformações:

\footnotetext{
${ }^{1}$ UFSC - Universidade Federal de Santa Catarina - Departamento de Língua e Literatura Vernáculas. Florianópolis - Santa Catarina - Brasil. 88040-900 - atilio.butturi@ufsc.br

${ }^{2}$ CREAS - Centro de Referência Especializada da Assistência Social - Prefeitura Municipal de Palhoça. Florianópolis - Santa Catarina - Brasil. 88040-900 - deniseadavila@hotmail.com 
primeiramente, com a construção de um novo corpo, feminino, pelos médicos; depois, pela inflexão tardia, na adolescência, para o gênero masculino (novamente) ${ }^{3}$.

O problema que John/Joan levanta, para Butler, é mesmo o da inteligibilidade e dos limites do verdadeiro. À Foucault, a questão da substancialização dos gêneros e do sexo (rei) é colocada em xeque e a pensadora questiona dois discursos axiais sobre o "caso": o primeiro, que considerava o gênero um enunciado de normalização e exigiu uma cirurgia “reparadora”, realizada pela medicina para circunscrever o corpo à suposta “realidade nova” do feminino, devidamente amparada pelos limites do binarismo heteronormativo; o segundo, de um transcendental biológico que exigia uma adequação endocrinológica, visto que os hormônios de John/Joan seriam uma espécie de destino, decisivo para uma identificação correta - o que redundaria, não obstante a cirurgia de mudança de genitália, na permanência de uma suposta natureza masculina para o sujeito em questão.

A operação de Butler ultrapassa esses dois limites do "verdadeiro sexo" ou do "verdadeiro gênero" e chama a atenção para o dispositivo sexual que exige ora a normalização, ora a adequação à biologia como destino. A crítica, dessa perspectiva, segue os passos foucaltianos e concentra-se no sujeito: John/Joan faz notar que "algo excede a norma” (BUTLER, 2006, p. 192, tradução nossa) e os limites da inteligibilidade de nossos regimes de verdade - sexual e genéricos. O problema que Butler faz notar diz respeito à não adequação de John/Joan a nenhum dos enunciados. Assim, quando ele/ela se posiciona em relação ao seu corpo, a posição do “eu” está “[...] entre a norma e a falha da norma” (BUTLER, 2006, p. 193, tradução nossa). As transformações da identidade de John/Joan empreendem, para Butler, uma discussão acerca dos limites da produção dos sujeitos em relação ao seu corpo, ao seu sexo, ao seu desejo. John/Joan, afinal, dessubjetifica-se. Dobra-se, criticamente, sobre os limites do binarismo.

É a partir dos limites que esse acontecimento trans ${ }^{4}$ traz à tona - conforme a

\footnotetext{
${ }^{3}$ Assim como fez Foucault com Herculine Barbin, o artigo de Butler contempla uma "vida infame" e seu caráter trágico. John/Joan e seu irmão gêmeo, ambos submetidos aos experimentos do dispositivo médicojurídico, desaparecem do mundo: John/Joan suicida-se aos 38 anos, enquanto seu irmão é encontrado morto depois de uma overdose de antidepressivos.

${ }^{4}$ Utilizamos trans neste texto para marcar a possibilidade de produção de autonomia diante do dispositivo da (trans)sexualidade. Como tentaremos mostrar, seguindo Butler (2004) ou Bento (2012), trata-se de estabelecer como possibilidade outras formas de objetificação e de subjetivação das pessoas trans, que transponham os limites da patologização e da anormalidade. Esse "acontecimento trans", aqui, refere-se às estratégias de resistência diante do que, adiante, chamaremos de dispositivo transexual ou da transexualidade. Já o uso de trans e "pessoas trans" refere-se ao esforço de deslocamento diante da
} 
ordem dos dispositivos - e sobre a possibilidade de questioná-los que o presente texto se volta. O objetivo é analisar a produção de discursos sobre as transgeneridades e as transexualidades que são materializados no dispositivo jornalístico brasileiro. Dessa perspectiva, definiu-se um corpus composto de textos informativos on-line do jornal Folha de São Paulo, versando sobre algum aspecto da transgeneridade no período de $1^{\circ}$ de agosto de 2014 e 3 de outubro de 2014. A hipótese é de que há uma regulação discursiva dos enunciados sobre o acontecimento trans, pautada em discursos de normalização e/ou discursos de naturalização, cujo resultado é a produção de discursos de abjeção e de patologização das subjetividades trans - o que ratifica, na materialidade do jornal, as hipóteses de Leite Jr. (2011), Butler (2004), Bento (2006, 2012), entre outros. Pretende-se, pois, entender os princípios que regulam os discursos, que mostram a rarefação imposta a eles na forma de um poder positivo. A fim de desenvolver a hipótese, o texto está construído em seções que versam: sobre alguns conceitos da arqueogenealogia foucaultiana; sobre o dispositivo (trans)sexual (FOUCAULT, 2009a; BENTO, 2006, 2012); sobre a análise do corpus.

\section{Discurso, Dispositivo e Poder}

Em A Arqueologia do Saber, de 1969, Michel Foucault define o enunciado como uma função. Antes disso, porém, recorre à suspensão das "unidades da continuidade" (FOUCAULT, 2012, p. 31), num trabalho negativo de desfazer a ilusão de realidade de conceitos como os de livro, obra, autor, expressão, tradição etc. Seu projeto é anunciado, então, como aquele que pretende descrever os acontecimentos discursivos, no seu jogo próprio de regularidade e de dispersão. Na Arqueologia, o enunciado é um acontecimento que “nem a língua nem o sentido podem esgotar” (FOUCAULT, 2012, p. 34), não obstante sua inscrição numa escrita e sua articulação num campo de memória, de remanência. As condições de repetição e acontecimento dos enunciados e as relações múltiplas que podem travar são determinadas por regimes de existência e coexistência, pela lei de repartição da dispersão dos enunciados que Foucault (2012) definiu como formação discursiva. Um enunciado pode pertencer a uma formação discursiva se

biomedicina e da identificação heteronormativa das variadas possibilidades de produção de sujeitos, corpos, afetos e prazeres sobre as quais as práticas trans têm chamado a atenção. 
obedecer a critérios relacionais complexos de produção e transformação de objetos, a saber, de conceitos, de modalidades de sujeito que enunciam e, ainda, de estratégias nãodiscursivas diferenciadas e que respondem a urgências históricas - nesse último caso, Deleuze (2005) ensina que se trata já de uma filosofia política na arqueologia, capaz de traçar a relação entre o sentido e condições de produção historicamente marcadas pelas lutas. Depois de discorrer sobre os enunciados - em suas relações múltiplas e políticas -, Foucault dá uma definição do que seria o discurso: “Chamaremos de discurso um conjunto de enunciados, na medida em que se apoiem na mesma formação discursiva” (FOUCAULT, 2012, p. 143)

Em 1970, em sua aula inaugural no Collège de France, ao apresentar o que chamou de procedimentos de logofobia que envolvem a produção e a circulação dos discursos, Foucault (2002, p. 59) retoma sua proposta de produção de uma "teoria das sistematicidades descontínuas". Ele exige o fim da "soberania do significante" (FOUCAULT, 2002, p. 51), cujo efeito teria sido o de relacionar o sujeito e os objetos a conhecer num sono antropológico balizado pela mediação universal. Sua proposta de descontinuidade, dessa perspectiva, passa a observar os procedimentos de exclusão e de codificação dos discursos e, além disso, convoca a se entender o discurso não como a expressão de um sujeito, nem como uma relação de referenciação, mas como objeto de uma luta incontornável e complexa, travada no interior de dispositivos específicos de saber-poder ${ }^{5}$.

Foucault apresentou algumas vezes - e de forma esquemática - esse conceito de dispositivo, em textos como A Vontade de Saber (FOUCAULT, 2009a) e em entrevistas, como a concedida à International Psychoanalytical Association, em 1977, em que ele discorre sobre o conceito como rede: “[é] um conjunto decididamente heterogêneo que engloba discursos, instituições, organizações arquitetônicas, decisões regulamentares, leis, medidas administrativas, enunciados científicos, proposições filosóficas, morais, filantrópicas. Em suma, o dito e o não dito são os elementos do dispositivo (FOUCAULT, 2009a, p. 244). Conceito que apela à mobilidade, o dispositivo é sustentado por uma teoria de poder também específica. Para Foucault, a cabeça do rei foi cortada e em seu lugar estabeleceu-se uma problemática do poder que funciona segundo vetores de força, numa

\footnotetext{
${ }^{5}$ Ao que parece, é uma vontade referencial que pretende, segundo a ordem do dispositivo, ordenar as práticas trans de acordo com o binarismo morfológico-sexual.
} 
rede de relações microfísicas e intercambiáveis, capazes de engendrar diferença, deslocamento e outras multiplicidades. Neste caso, o reino é da micropolítica e o dispositivo é, pois, o conceito operacional exigido por essa anatomia política do poder (FOUCAULT, 2013, p. 29).

A dependência entre uma teoria do poder microfísica e o conceito de dispositivo é discutida de forma exemplar por Giorgio Agamben. Para o filósofo italiano, “dispositivo” corresponde a um termo técnico essencial na arquitetura do pensamento foucaultiano. Agamben (2014) faz notar justamente a relação entre os dispositivos e os viventes, como apontava Foucault, cujo vértice-resultante seria o sujeito. Na contemporaneidade, então, a multiplicidade dos dispositivos inflacionaria a categoria de subjetividade, numa série irrefreável e microfísica de "processos de subjetivação" (AGAMBEN, 2014, p. 40). Tal miríade teria como consequência a perda de uma consistência subjetiva e, no limite, o questionamento da consistência que esta subjetividade detinha até então, por aquilo que, via Foucault, aprendeu-se a chamar de filosofias antropológicas ou da consciência.

Porém, a captura dos dispositivos circunscrita ao governo contemporâneo, como ensinou Michel Foucault, traz no bojo a implicação do fim de sua capacidade de resistência, entendida por Agamben (2014) como um “eclipse da política”, o fim de uma perspectiva de profanação e de autonomia - o que o italiano aproxima da "catástrofe". A tarefa de Agamben (2014, p. 51) é justamente a da “profanação dos dispositivos”, num processo ético caro ao "último Foucault". Como se sabe, a instância de resistência e liberdade que o francês formulava exigia uma des-subjetivação. Haveria três tipos de luta: contra as formas de dominação, contra as formas de exploração e, a mais urgente, “[...] as que combatem tudo o que liga o indivíduo a ele mesmo e garante, assim, sua submissão aos outros [...]” (FOUCAULT, 2014a, p. 123). Sob tal égide, quando se questiona sobre “quem somos nós?”, Foucault já prevê a exigência da "profanação” (conceito de Agamben) dos dispositivos e das subjetividades codificadas e governadas que eles engendram. A "tarefa filosófica” da atualidade é a de recriação das relações de subjetividade dos dispositivos, em práticas éticas e de liberdade (BUTTURI JUNIOR, 2016). Destarte, sua recusa de "ser o que somos" redunda nas chamadas "invenções de si”, cujo funcionamento é crítico e plástico diante dos dispositivos de poder-saber. Lutas agonísticas diante de suas estruturas e da individuação (dos dispositivos), são uma relação 
de nunca acabar e que exigem formas de subjetividade des-subustancializadas: "Mais do que um 'antagonismo' essencial, valeria mais a pena falar de um 'agonismo' - de uma relação que é, ao mesmo tempo, de incitação recíproca e de luta.” (FOUCAULT, 2014a, p. 134).

A partir da breve conceituação da problemática dos discursos e dos dispositivos aqui efetuada, a próxima seção se voltará para o dispositivo da sexualidade - e da transexualidade - e de sua produção dos viventes sexuados, dos gêneros e da possibilidade de transgressão e reinscrição das formas de subjetividade.

\section{O Dispositivo (Trans)sexual}

Partindo das discussões precedentes acerca do discurso, é o momento de descrever o que Foucault entende como o dispositivo da sexualidade. Em História da Sexualidade I: a Vontade de Saber, Foucault (2009a) faz um resgate da produção de saberes sobre o sujeito, o poder e as práticas de desejo, apresentando seus diversos deslocamentos basicamente, de uma ars erotica, passando por um discurso da carne, até chegar ao dispositivo sexual e a scientia sexualis, no século XVIII. Como afirmava já na Arqueologia..., tais deslocamentos não tratam da continuidade, mas da cesura e dos deslocamentos. Assim, o acontecimento do dispositivo sexual denega a possibilidade de uma história referencial - nesse caso, sobre "a” sexualidade ou "o "sexo”, mas faz notar um funcionamento do poder diferente, formas de subjetividade específicas, produção de objetividades reguladas e marcadas.

A hipótese geral do livro é de que o sexo e a sexualidade não foram reprimidos a partir do século XVIII e no XIX, na época vitoriana. Pelo contrário, o acontecimento foi o de uma ubiquidade e de uma injunção do dizer. Foucault (2009a) relaciona o sexo, saber e poder, apontando que se trata de um dispositivo de "prazer-saber" que passa a exercer a atividade de chave universal de inteligibilidade dos sujeitos. Sua "analítica do poder" esclarece que não se trata de silenciamento ou de um uma prática jurídica, mas de incitação e de práticas polimorfas de saber-poder. É preciso, pois, investigar a sexualidade como um dispositivo, um jogo de relações múltiplas e de táticas e estratégias de confronto, produção e transformação, cujos produtos, a partir do século XIX são a ontologização do desejo e a normalização dos sujeitos. Assim delineado, o dispositivo da 
sexualidade teria sido produzido, a partir do século XVIII, em quatro estratégias: histerização do corpo da mulher, pedagogização do sexo da criança, socialização das condutas de procriação e psiquiatrização do prazer perverso. Foucault (2009a, p. 116) assim o define:

\begin{abstract}
A sexualidade é o nome que se pode dar a um dispositivo histórico: não à realidade subterrânea que se apreende com dificuldade, mas à grande rede da superfície em que a estimulação dos corpos, a intensificação dos prazeres, a incitação ao discurso, a formação dos conhecimentos, o reforço dos controles e das resistências, encadeiam-se uns aos outros, segundo algumas grandes estratégias de saber e de poder.
\end{abstract}

De modo similar ao que fizera em Vigiar e Punir (FOUCAULT, 1987), Foucault mostra que o importante é notar a relação do poder-saber e a produção de uma “alma”, relacionada aos discursos das ciências humanas (psicologias, psiquiatrias, medicinas, pedagogias etc.) e a injunção de falar de si e de seu desejo, fundante de um modelo de subjetividade que ainda nos diz respeito.

É segundo essa ordem do dispositivo que se podem descrever as práticas discursivas relacionadas aos enunciados trans. Foucaultianamente, então, é mister implicar o dispositivo sexual e a produção dos anormais (os “perversos”), cuja primeira aparição teria se dado na problematização da monstruosidade. Em Os Anormais, série de cursos de 1975, Foucault (2001) ensina que o problema do “monstro humano” é o modelo sobre o qual a anormalidade se desenha - o anormal sendo, então, "um monstro banalizado” (FOUCAULT, 2001, p. 71). O monstro, assim como o anormal, traz no bojo um problema de inteligibilidade, porque não pode ser definido pelos saberes. Torna-se o modelo ideal da discrepância.

Ora, Foucault (2001) traça uma série de discursos da monstruosidade: na Idade Média, o monstro privilegiado era o homem bestial; no Renascimento, os siameses. Eis que no século XVIII, o dispositivo de normalização - diríamos, da sexualidade e da normalização - trazem ao centro uma nova forma de monstruosidade: o hermafrodita, monstro por excelência da Época Clássica, conforme lida por Michel Foucault. O ponto nevrálgico da mudança acolhe duas transformações axiais: a monstruosidade do hermafrodita está relacionada a transgressões de várias ordens de um dimorfismo sexual; o hermafrodita, de modo mais relevante, indica a passagem do século XVII para o século XVIII, de um regime estritamente biológico (no século XVII, o desvio do hermafrodita é 
apenas natural) para um problema da moralidade do sujeito, de sua periculosidade, de sua criminalidade a espreitar. O hermafrodita dos séculos XVIII e XIX passa à anormalidade: é um criminoso em potencial e um desvio da natureza corporificado na forma de um sujeito, sobre o qual os saberes precisam se aplicar. Como “monstro moral” primeiro, ele é a figura do deslocamento do saber-poder, configurado em técnicas infinitesimais e microfísicas de extração da verdade dos indivíduos. Banalizado em sua problemática biológico-moral, a fábula que carrega é o mote para a produção da perversidade e para as estratégias de normalização que lhe são correlatas (FOUCAULT, 2009a, 2001) ${ }^{6}$.

No Brasil, a política higienista se vale de uma apropriação da literatura médica de patologização dos prazeres perversos. Um dos livros mais antigos na abordagem da díade sexo-anomalia e que gozou grande popularidade durante a primeira metade do século XX no Brasil é o de Hernani Irajá, Psicoses do Amor, cuja primeira edição é de 1917, mas que recorre aos "mestres higienistas europeus", sobretudo de Krafft-Ebing (BUTTURI JUNIOR, 2012). Em seu Psychopathia Sexualis (2001), de 1886, o alemão discorre sobre os graus de desenvolvimento do que chama de "sexualidade antipática”. Destarte, a genealogia do dispositivo sexual, da perspectiva de uma psiquiatrização dos corpos perversos no Brasil, exige que se pontue, pois, o papel importante que se reserva aos discursos de inversão e hermafroditismo e, a partir daí, a rede que produzirá um dispositivo da transexualidade. No caso brasileiro, Bento (2006) traça as estratégias médico-políticas de produção do "verdadeiro transexual”, segundo sua versão psicanalítica (Robert Stoller) ou sua versão biológica (via Henry Benjamin e seu “transexual verdadeiro”). O que a autora brasileira faz notar é a implicação entre a definição de protocolos e universalização de uma identidade médica transexual. O resultado é a produção de um dispositivo transexual que, ubuescamente, legitima-se segundo estratégias discursiva e não-discursivas que se originam na incomensurabilidade sexual e a partir da crença de que os conflitos residem nos sujeitos trans e não são resultados das normas político-sociais. Seguindo Berenice Bento, Borba (2014a, 2014b) ratifica a genealogia desse dispositivo transexual, apontando nos mecanismos internacionais de classificação das pessoas trans (DSM e CID, sobretudo) a permanência de enunciados sustentados pela produção dos discursos acerca do "transexual

\footnotetext{
${ }^{6}$ Esse corpo sexuado e seus problemas político-morais, tomados como questão-chave para os saberes sobre os sujeitos, serão problematizados, seguindo Foucault e outras bases teóricas, pelos debates de gênero contemporâneos, objeto da próxima seção.
} 
verdadeiro”, que têm na matriz heterossexual a raiz explicativa e que reduzem as práticas trans a identidades monolíticas e assujeitadas pelos dispositivos biopolíticos.

Diante das discussões que se travam a respeito da patologização, no entanto, alguns debates e alternativas têm aparecido, buscando a resistência e a autonomia das pessoas trans (BUTLER, 2004; ARÁN; MURTA; LIONÇO, 2009; BORBA, 2014a, BENTO, 2012, LEITE JUNIOR, 2011, JESUS, 2016) e a produção de discursos e práticas que levem em consideração o caráter performativo das identidades. No Brasil, além das discussões acadêmicas, uma série de tensionamentos têm se produzido desde 1979, quando a modificação da identidade sexual ainda era passível de criminalização por falsidade ideológica (ARÁN; MURTA; LIONÇO, 2009). A partir de 2002, os procedimentos de adequação, não obstante seu caráter ainda patologizante e naturalizante, passam a ser permitidos em hospitais públicos e privados. Em 2008, depois de longo período de reivindicação e de atuação política das pessoas trans, a Portaria 1.707 do Ministério da Saúde institui o Processo Transexualizador no SUS, pautada em enunciados de humanização e de ausência de discriminação, de forma a respeitar as diferenças e atentar para os processos de diálogo entre os trabalhadores e as trabalhadoras da saúde e as pessoas trans (ARÁN; MURTA; LIONÇO, 2009; BORBA, 2014b).

Tais processos de luta discursiva no interior do dispositivo transexual ainda permanecem, como se sabe, bastante incipientes e ainda dependentes do dispositivo biomédico. Produzindo resistência e inventariando práticas criativas, porém, as problematizações do feminismo e das/dos ativistas e teóricos/as têm evocado outra chave explicativa para o acontecimento trans - o que será abordado nas próximas seções.

\section{Gênero e sexo: para além do fundacionalismo biológico}

Quando se discutem questões como a da sexualidade e dos gêneros, é comum que se faça uma distinção entre aquilo que é da ordem da natureza, o sexo e suas características biológicas e/ou anatômicas, e aquilo que é da ordem da construção social, o gênero. O gênero, nessa chave de leitura, seria apenas um epifenômeno de uma realidade biológica inata, de uma substantividade metafísica (STRYQUER, 2008). Neste artigo, todavia, não se partirá dessa cisão entre a biologia e a socialização, justamente porque o solo é o dos dispositivos foucaultianos. Ao invés de se imaginar o "sexo" 
inaugural e raiz de todos os gêneros, seguiremos alguns posicionamentos das teorias contemporâneas que problematizam a díade.

Iniciemos com Laqueur (2001, p. 27), que pontua uma relação de constituição discursiva para o corpo, para a biologia e para o sexo: "O sexo, como o ser humano, é contextual.". Para Laqueur (2001) - fundamental na discussão trans brasileira de Bento (2006) e outros/as, não há uma natureza masculina e feminina primeira, sobre o qual os saberes se debruçam. Pelo contrário, a diferença entre os sexos é constituída por dispositivos de saber-poder. A tese fundamental é a de que a ideia moderna de um dimorfismo sexual e de características incomensuráveis entre dois sexos - ou seja, de uma diferença total entre o masculino e o feminino - são uma invenção recente, da ordem da scientia sexualis (BUTTURI JUNIOR, 2012).

O debate de Laqueur é contemporâneo daquele dos feminismos. Esses “movimentos feministas” iniciaram suas reinvindicações com a perspectiva de sufrágio universal, equiparação salarial e passaram a assumir uma agenda indagadora das funções sociais do sexo e do gênero, tidos inicialmente como distintos. Nicholson (2000), em Interpretando o Gênero, mostra como o conceito 'gênero' apareceu na problematização dos feminismos como uma construção cultural de atribuições sociais designadas a partir de uma suposta condição biológica da sexualidade. Assim, comportamentos, personalidades, papéis, atividades, funções e caráter sociais seriam conferidos dentro do discurso dominante, a posteriori, segundo uma cisão prévia dos sexos - o masculino e o feminino, então incomensuráveis. Nicholson explora a necessidade da corrente feminista de abandonar o determinismo e o fundacionalismo biológico, criticando a ontologização do sexo como diferença última entre os sujeitos. A autora lança mão, ainda, de um debate sobre os transexuais, cuja ambiguidade aponta exatamente para o caráter de jogo de linguagem dos corpos sexuados e pelas variações que fazem entrever.

Trabalhando o gênero existente em uma prática discursiva, nos moldes estabelecidos por Michel Foucault, Judith Butler, em Problemas de gênero, também desconstruirá a dicotomia sexo e gênero - e suas consequências substancialistas. Ela sinaliza que o sujeito só existe na produção dos dispositivos de poder-saber, que o generificam. Invertendo o fundacionalismo biológico e colocando em xeque a separação entre a biologia e a cultura, aponta que é o dispositivo da sexualidade que cria tanto o sexo quanto o gênero. Nesse caso, os discursos de gênero, binários, são o locus para se 
produzir o dismorfismo: “[...] O gênero é a estilização repetida do corpo, um conjunto de atos repetidos no interior de uma estrutura reguladora altamente rígida, a qual se cristaliza no tempo para produzir a aparência de uma substância, de uma classe natural de ser. [...]” (BUTLER, 2015, p. 69).

Butler (2015) toma a discussão da performatividade da leitura derridiana de Austin. Os performativos são enunciados que prescindem de condições de verdade (os enunciados constativos têm tal função) e exigem apenas ação, condições de felicidade e infelicidade, elaboradas socialmente. A teoria da performatividade generalizada, então, seria uma transposição da diferença entre enunciados constativos e enunciados performativos, afirmando a condição de asserção sobre o mundo dos segundos como forma de construtivismo. Para Butler, os gêneros e o sexo são performativos, atos estilizados do discurso, sedimentados por práticas sociais e, no limite, pelo dispositivo sexual heteronormativo ${ }^{7}$.

Entretanto, Butler (2015) afirma que as problematizações de gênero e do binarismo masculino e feminino, como as duplicações das drags e os vários modelos de travestismo e de trans serviriam como experiências limítrofes, críticas em relação aos dispositivos e à normalização enunciada por Michel Foucault ${ }^{8}$. Assim, ela lança um questionamento fundamental acerca da liberdade e das resistências, cujo locus são os discursos, corpos e sujeitos que se encontram, de alguma forma, do outro lado da heterossexualidade normativa. Questiona, então, quais performativos podem produzir outras formas de subjetificação e de objetificação e quais práticas, portanto, podem ser mais subversivas diante da plasticidade do poder. A autora observa que estratégias como o butch, o femme e os fucking genders exigem que se opere dentro do dispositivo da sexualidade e proporcionam, à Derrida, condições de iterabilidade e instabilidade: desfaz-

\footnotetext{
${ }^{7}$ Estamos aqui tomando a heteronormatividade de acordo com a perspectiva queer (pautada, por sua vez, em estudos de Foucault e Derrida) como um dispositivo que produz formas de objetificação - discursos e práticas - e formas de sujeito de acordo com princípios de normatização baseados na incomensurabilidade natural dos gêneros e na heterossexualidade compulsória como norma social que produz corpos abjetos e sujeitos anormais segundo a ordem da natureza e da adequação (LAQUEUR, 2001; BUTLER, 2015, FOUCAULT, 2009a). No que se refere às pessoas trans, é mister acrescentar que a problemática da heterossexualidade compulsória também é uma questão premente, que relaciona o acontecimento trans à injunção de adequação ao binarismo, mediante procedimentos cirúrgicos e de medicalização, não levando em conta a miríade de práticas corporais e subjetivas que podem ser engendradas pelos sujeitos.

${ }^{8}$ Sob tal égide, a crítica chega até Foucault, quando esse estabelece (para tratar de Herculine Barbin, hermafrodita do século XIX sobre cuja vida infame Foucault se debruçara), segundo ela, uma transgressão para além do discurso. De acordo com Butler (2015), é preciso promover a subversão no discurso e nos dispositivos e não há nada que possa sugerir um reino da liberdade sem linguagem ou sem relações de poder.
} 
se o caráter substancialista da sexualidade e exige-se sua superação, na forma da disseminação dos gêneros.

Butler, ao menos em outra ocasião, volta-se para o caráter de resistência e de subversão performática subsumido em sua discussão dos gêneros. Assim, em Corpos que pesam $^{9}$, a autora retoma a discussão sobre os abjetos como “recurso crítico” (BUTLER, 2002, p. 156) de desidentificação diante das normas regulatórias que produzem o dimorfismo sexual e a substancialização das identidades de gênero. A autora novamente recorre a Foucault para estabelecer uma discussão que não redunda em construcionalismo linguístico radical, mas relaciona discurso e corpo. É nesse momento que se vale de Derrida e da citacionalidade, indicando que a atividade de nomeação e de categorização - e, por conseguinte, de produção de discursos sobre os corpos, a sexualidade e os gêneros - é uma assunção de normas performativas e derivadas, sem um núcleo universal e necessário capaz de garantir a estabilidade. Destarte, se os gêneros são performativos, algumas consequências são solicitadas: a heterossexualidade é uma norma pela qual os sujeitos se generificam, de forma não-livre; as identificações de gênero interpelam os sujeitos em suas produções identitárias; e, por fim, a norma performativa produz fronteiras abjetas, corpos que fracassam em produzir-se no regime de verdade estabelecido pela norma heteronormativa - e apontam, justamente, para sua citacionalidade radical.

Adiante, no capítulo O Gênero em Chamas, Butler (2002) irá tomar o documentário Paris is Burning para ratificar sua posição. Para ela, há na ambivalência retratada no filme, justamente nos discursos de "realness", de “passamento", nos quais os sujeitos - drags, travestis, trans - detonam de forma parodística e ambivalente a norma heterossexual. Butler (2002) nota que, ao mesmo tempo em que uma cultura heterossexual hegemônica exige certos modelos de identificação dos homossexuais latinos, pobres, mestiços e negros do documentário, também a citação da norma pode sugerir resistências. O que se tem, então, é uma agonística: nem a inssurreição completa e a liberdade dos novos gêneros possíveis, tampouco uma subordinação total à norma. É a ambivalência, portanto, que interessa, enquanto incapacidade de produção de performativos felizes - ou de identidades de gênero estáveis (BUTLER, 2002).

\footnotetext{
${ }^{9}$ Utilizamos aqui a tradução argentina do texto de Butler, Cuerpos de Importan, publicada em 2002. O texto original é de 1993.
} 
Certamente, tal dimensão de ambivalência pode ser amplamente discutida, como fazem, por exemplo, Prosser (2006) ${ }^{10}$ ou Preciado (2002). Prosser (2006) traz à tona de modo enfático a própria auto-crítica de Butler, questionando o lugar que os discursos de travestismo e de transexualidade poderiam ocupar na resistência efetiva ao dispositivo sexual. Tanto Prosser quanto Preciado subvertem a lógica do discurso butleriano ao invocar a personagem Venus Xtravaganza, de que Butler parte para analisar parodisticamente os gêneros em Bodies that Matter. Para ambos, o problema do “realness", de passar por (mulher, branca, de classe abastada etc.), supostamente subversivo, esbarra na infelicidade (para ficar em termos austinianos) de um corpo levado à finitude (Xtravaganza é assassinada por um cliente, como Butler já notava) e à corporalidade tecnologicamente marcada das travestis e transexuais, da "incorporação" (PRECIADO, 2002, p. 75) que não pode redundar apenas nos discursos de negação de identidade de gênero, mas exigem uma espécie de retorno a Foucault (em Preciado) no debate sobre a própria condição do corpo sexuado e de suas formas tecnológicas de produção de diferença e subjetividades.

Não obstante as críticas e os limites possíveis da ambivalência trans, é a perspectiva agonística de relações de poder e de resistência no dispositivo sexual que ela oferece que interessa ao presente trabalho. Para além de uma liberdade radical operada pelas modalidades queer, o que se defende é uma luta constante entre o dispositivo e suas maquinarias (discursiva ou não), sempre derivadas mas cuja injunção é de mediar as relações entre os viventes (tornados sujeitos) e o mundo. Inquirir os discursos acerca de trans é a tarefa de interrogar sobre uma profanação possível e não de uma garantia de resistência inerte, descorporificada ou des-codificada.

Isto posto, passemos a uma breve discussão conceitual de trans.

\section{Sobre Trans}

Iniciamos esta subseção a partir de um discurso médico. No ano de 1994, o Manual Diagnóstico e Estatístico das Desordens Mentais IV (DSM-IV) nomeava a transexualidade como transtorno mental. A edição de 2013 desloca o problema da

\footnotetext{
${ }^{10}$ Prosser (2006) mostra que, em textos mais recentes, Butler retoma o problema a partir da leitura da melancolia heterossexual, na tentativa de desfazer a relação apenas de liberdade que as experiências trans produziriam.
} 
classificação e aborda a transexualidade como diagnóstico de transtorno mental, chamando-a de ‘disforia de gênero’ nos seguintes termos nosológicos:

Incongruência acentuada entre o gênero experimentado/expresso e o gênero designado de uma pessoa, com duração de pelo menos seis meses, manifestada por no mínimo dois dos seguintes:

1. Incongruência acentuada entre o gênero experimentado/expresso e as características sexuais primárias e/ou secundárias (ou, em adolescentes jovens, as características sexuais secundárias previstas).

2. Forte desejo de livrar-se das próprias características sexuais primárias e/ou secundárias em razão de incongruência acentuada com o gênero experimentado/expresso (ou, em adolescentes jovens, desejo de impedir o desenvolvimento das características sexuais secundárias previstas).

3. Forte desejo pelas características sexuais primárias e/ou secundárias do outro gênero.

4. Forte desejo de ser tratado como o outro gênero (ou como algum gênero alternativo diferente do designado).

5. Forte convicção de ter os sentimentos e reações típicos do outro gênero (ou de algum gênero alternativo diferente do designado).

B. A condição está associada a sofrimento clinicamente significativo ou prejuízo no funcionamento social, profissional ou em outras áreas importantes da vida do indivíduo. (DSM-V, 2014, p. 451)

Nas crianças ainda se acrescenta como sintomática a preferência por brinquedos, jogos e brincadeiras e uso de papéis sociais fantasiosos divergentes ao gênero de nascimento, forte preferência pelo cross-dressing (o chamado travestimento). A chamada ‘disforia de gênero’ tem correspondência no Código Internacional de Doenças, o CID ${ }^{11}$, amplamente questionado nos estudos sobre as pessoas trans - conforme Butler (2004), Bento (2006), Leite Junior (2011), Bento e Pelúcio (2012), Jesus (2016), Borba (2014a) - por implicar num dispositivo de psiquiatrização dos corpos, cuja genealogia remonta à medicina do século XIX e à tentativa de redução da diversidade de modalidades de identificações e performances que, a partir de critérios discutíveis e politicamente construídos, redundam numa simplificação das formas de subjetividade a partir da “[...] coerência essencial entre sexo biológico e gênero” (ARÁN; MURTA; LIONÇO, 2009, p. 1143).

\footnotetext{
${ }^{11}$ Desde 1980, a condição transexual aparece no DSM (DSM-III). No Brasil, as primeiras discussões legais de procedimentos de transgenitalização aparecem em 1979, conforme relato de Arán, Murta e Lionço (2009).
} 
Façamos uma contraposição entre os enunciados patologizantes que se leem acima e o texto de Enke (2012), quando a autora apresenta o aparecimento do conceito de cisgênero, nas ciências humanas e sociais, relido da biologia, justamente em 1994: o prefixo cis- diria respeito à atividade intramolecular, enquanto trans- voltar-se-ia a atividades entre moléculas diferentes. Enquanto cis- recorre a movimentos na mesma direção, trans- indica, no nível molecular, a assunção de uma pluralidade de direções. Por fim, cis- é uma característica do que não sofre modificação de estado na dependência do meio; trans-, ao contrário, aponta para a subversão e para a modificação em contextos variados. Enke (2012) mostra a rápida disseminação do uso dos prefixos como conceitoschave dos movimentos ligados à sexualidade e ao gênero na universidade. No uso mais comum, cisgênero implicaria a permanência e a assunção em certos parâmetros culturais e normativos de gênero, enquanto trans e cross trariam no bojo a disjunção com tais parâmetros - aqui não se considerando a exigência de subversão e de resistência. Para Enke (2012), a discussão cis vs. trans promoveu tanto a politização das formas de subjetividade genericamente constituídas quanto foi capaz de estabelecer uma ferramenta conceitual que não esbarrasse no binarismo (masculino e feminino) já solidificado. Ademais, a autora faz notar que os discursos trans permitiram, inclusive, engendrar propostas de suspeição da regulação cis.

Os dois excertos, do DSM e de Enke (2012), revelam o caráter de luta discursiva que envolve, atualmente, a irrupção de práticas não normativas de subjetividade, de corporalidade e de gênero. Se, por um lado, avançam os processos de medicalização e psiquiatrização de uma suposta “disforia”, por outro lado assiste-se à ampla produção teórica e política de reinscrição das práticas em modelos de subversão da matriz binária e heteronormativa. No presente texto, certamente trata-se de observar os discursos médicos sob a égide dos processos de anormalização do dispositivo sexual. Por conseguinte, cabe aqui investigar as possibilidades de dar voz aos - ainda - abjetos e reivindicar um entre-lugar possível para as práticas de subjetivação relacionadas ao desejo.

Partindo daí, a própria rede enunciativa que recobre trans pode ser lida discursivamente. O conceito de transgênero, por exemplo, teria emergido da capacidade de problematização da matriz heteronormativa. Stryquer (2008) aponta que o surgimento do conceito obedece a táticas de resistência, cujo intuito é destituir de legitimidade as 
injunções de relacionar o sexo e o gênero. Transgênero revela uma distinção axial. Enquanto o conceito de transexualidade - cuja produção se deu no início do século XX, via Magnus Hirshfield, e cuja popularização se deu na década de cinquenta do século XX - carrega a memória de enunciados médicos e biológicos, de adaptação e submissão da morfologia ou de inadequação patológica, a transgeneridade, que ganha notoriedade no início dos anos 2000, sobretudo nos Estados Unidos, açambarca formas variadas de práticas corporais e identitárias. Assim, tansgênero evoca as diversas combinações possíveis entre as duas discursividades - do corpo sexualizado e dos gêneros. Aqui, é de um solo arqueogenealógico distinto que se enuncia, no esforço de romper as barreiras culturais. Diríamos, num esforço cross/trans.

No Brasil, diversos autores chamam a atenção para o deslocamento da problemática trans, no sentido de uma resistência diante do dispositivo médiconaturalista e, ainda, de uma efetiva produção da cidadania das pessoas trans que não seja pautada na patologização e que possa atender à “atenção integral” já estipulada pelos documentos oficiais desde 2008 (ARÁN; MURTA; LIONÇO, 2009; BORBA, 2014a, 2014b; BENTO, 2012, LEITE JUNIOR, 2011, JESUS, 2016). Como aponta Jesus (2016; JESUS; ALVES, 2012), é sobre o discurso de cidadania que deve incidir a discussão, sobretudo porque o que está em jogo é um dispositivo de racialização ampliado, conforme descrito por Foucault (2010), que atinge os corpos abjetos e que não logra alcançar os limites discursivos da "humanidade".

Destarte, da perspectiva da resistência e da autonomia, a dicotomia trans/cis opera taticamente, exigindo a visibilidade de formas de subjetivação que não se enquadram na causalidade do corpo sexuado. Ademais, traz à tona o caráter performático do masculino e do feminino, desestabilizando o solo naturalizador do dimorfismo sexual. A resultante é contestatória em duas vias, pois interdita os discursos de ontologização já mencionados anteriormente (FOUCAULT, 2009b) e faz proliferar novas formas, visíveis e múltiplas, a partir das matrizes culturais e históricas de que tomamos parte. No caso do Brasil, além da discussão acadêmica, a organização de um transfeminismo como ação coletiva de resistência tem se dado a partir de 2010 e está pautada em ações que reconhecem o estatuto discriminatório cissexista do dispositivo transexual (JESUS; ALVES, 2012). 
Tendo tais problematizações e práticas em vista, então, neste artigo entendemos trans como uma série de enunciados múltiplos, cuja pretensão é a de colocar em xeque a circunscrição dos dispositivos. É assim que faremos referências às práticas de subjetivação e de objetivação que ultrapassam, de formas variadas, o caráter de substancialização da sexualidade e das corporalidades binárias. Entretanto, o que se observará na análise dos discursos é, ainda, a manutenção de categorias que tomam como ponto de partida regimes de dizer codificados do dispositivo transexual brasileiro: da ordem médico-psiquiátrica, da ordem do silenciamento, da ordem da substancialização. Vejamos como isso acontece no dispositivo midiático do jornal Folha de São Paulo.

\section{O Dispositivo Jornalístico e o Dispositivo da Transexualidade}

O jornal Folha de São Paulo, objeto de nossa análise, surgiu na década de vinte do século XX; como um dispositivo jornalístico, discursivo e não-discursivo e marcado por estratégias e urgências históricas, apresenta-se como apartidário, crítico e pluralista em seu projeto editorial (FOLHA DE SÃO PAULO, 2016). Segundo dados on-line, o jornal conta com uma distribuição nacional e uma tiragem de aproximadamente 300 mil exemplares. O perfil socioeconômico de seus leitores (de março de 2016) é o seguinte: $86 \%$ pertencentes à classe social A e B; 52\% é do sexo masculino (não há qualquer referência ao problema categorial que envolve as classes ou a sexualidade); 74\% possui idade superior a 24 anos. Os hábitos de seus leitores também foram medidos e são elencados pelo jornal: 76\% têm casa própria, 70\% compram em shoppings, 85\% têm acesso à internet. Em suas pesquisas de opinião, constatou-se que a maioria dos leitores é favorável a pautas progressistas (liberalização do aborto, reforma agrária e descriminalização da maconha). Na listagem dos supostos “dados”, chama a atenção o posicionamento dos leitores da Folha quanto à união homoafetiva: o público leitor ainda resiste, sendo metade de seus leitores contrários à união (FOLHA DE SÃO PAULO, 2016). 
A posição-leitor e a posição-autor da Folha estão materializadas no corpus desta pesquisa, a saber, textos informativos on-line publicados entre $1^{\circ}$ de agosto de 2014 e 3 de outubro de 2014. O discurso trans aparece materializado segundo a tática de normalização que rivaliza com estratégias discursivas de vanguardismo e liberalização de que se vale a Folha, justamente a partir da posição-leitor, marcada por um suposto liberalismo nos costumes (MOTA, 2000).

A fim de inteligir esse embate discursivo, podemos suscitar a hipótese de que a Folha produz duas estratégias, constitutivas mas opostas: de um lado, relaciona-se com discursos liberalizantes, dando-lhes alguma positividade e legitimidade - como no caso da ampla cobertura dos “casamentos” homoafetivos e o caso da cantora Daniela Mercury, em 2013; do outro lado, a Folha retoma uma memória discursiva composta de préconstruídos relacionados aos discursos de normalização, circunscritos ora a enunciados de estigmatização, ora a um funcionamento excludente e silenciador. Tal estratégia dual não apenas constitui a posição de autoria do jornal, na forma do dispositivo, quanto permite dizer e deslocar enunciados sobre a liberalização e a normalização. Nesse caso, podemos partir da hipótese de que se trata de duas Formações Discursivas (FD), responsáveis por leis de coexistência e dispersão de enunciados e de produção de objetos, conceitos, modalidades enunciativas e estratégias. Tais Formações Discursivas, para Foucault (2012), não circunscrevem os dizeres a partir de uma realidade ideal, mas estão em confronto contínuo e múltiplo, na ordem de poderes microfísicos e de resistências que podem se materializar nos textos do jornal.

Iniciemos a discussão sobre tal embate - entre uma FD Liberalizante e uma FD Normalizadora - levantando um argumento numérico: no período pesquisado, menos de quinze textos voltam-se aos discursos trans, considerando nesse número aqueles que apenas mencionam tais discursos de modo periférico (a grande maioria) ou como epifenômeno dos discursos relacionados à união estável homoafetiva (cara às páginas da Folha). Os enunciados que percorrem esses textos recorrem a três discursos, que materializam e retomam o dispositivo transexual brasileiro (BENTO, 2006): o do pastiche e da espetacularização; o da anormalidade e da medicalização; o de uma legalidade, da ordem dos direitos individuais.

Observemos a primeira das estratégias relacionada à materialização dos discursos trans. A Folha, cuja estratégia, como se viu, é de assunção de um discurso liberalizante, 
circunscreve a aparição dos enunciados sobre trans a colunas de artes e espetáculos ou à personalização midiática. Expliquemos: no corpus analisado, sete são relacionados ao universo do entretenimento, em sentido amplo. Assim é que, em 25 de setembro de 2014, há uma breve menção do desempenho de um ator global como “o travesti” no espetáculo Hedwig e o Centímetro Enfurecido (FELTRIN, 2014). Já em 26 de setembro de 2014, a Ilustrada traz o texto Crítica: Série 'Transparent' humaniza a questão de gênero. O texto discorre sobre a aparição menos estereotipada das práticas trans - “[...] é frequente e secreta, lutando para se fazer reconhecer e derrotar o estigma social que a associa, na visão do fundamentalismo conservador, com a perversão e a doença.” (COUTINHO, 2014, [n.p.]). Assinado pela cartunista Laerte Coutinho, talvez a autora trans cuja voz se faz mais presente no jornal, o lugar institucional que ocupa é, não obstante, o dos discursos não-sérios da arte e do entretenimento (AUSTIN, 1990), pautados numa visão menos objetiva de "crítica” (nesse caso, note-se, ainda, que Coutinho não escreve com frequência as críticas de Ilustrada).

Façamos um parêntese. Voltando-nos para a miríade de relações enunciativas que a Folha trava, notamos que em texto anterior, de 9 de março de 2014, Laerte também figurava entre as/os transexuais que inauguravam um padrão mais normalizador e, em tese, invadiam o mercado de trabalho. Ainda que não componha o corpus de análise deste artigo, o texto aponta para estratégias discursivas díspares e para uma memória importante: por um lado, exorta o leitor a estabelecer uma visão menos "preconceituosa”, dando, inclusive, voz a diversas transexuais e mulheres transgênero (não se lê depoimentos de homens trans); por outro, esclarece as práticas segundo o discurso médico, cuja aparição é anterior aos depoimentos. Novamente, a estratégia é a da legitimidade dos enunciados da ciência e do fundacionalismo biológico na produção das corporalidades trans, lidas em sua condição de pacientes psiquiátricas:

Para o psiquiatra Alexandre Saadeh, coordenador do laboratório que atende a este público no Hospital das Clínicas, "embora tenham corpos masculinos, as transexuais se percebem como mulheres e têm de ser tratadas assim". [...] Seu trabalho é acompanhar as pacientes que decidem encarar cirurgias de mudança de sexo. (SENRA, 2014, grifo nosso, [n.p.])

Fechemos o parêntese, lembrando que aqui ainda se trata da produção de subjetividades trans segundo a ordem do dispositivo biomédico e transexual (BENTO, 
2016; TENÓRIO; PRADO, 2016; BORBA, 2014a; BUTLER, 2014; LEITE JR., 2011).

Buscando o que aqui chamamos de “visibilidade midiática”, o jornalista televisivo Marcelo Tas narra sua experiência com a transexualidade do filho, na coluna Celebridades, do F5 (canal on-line dedicado aos mexericos de celebridades nacionais e internacionais). A mesma sorte terão as manifestações trans em dois textos que versam sobre a cantora Miley Cyrus, publicados em 26 de setembro e 29 de setembro de 2014. Primeiramente, ambos também figuram nos cadernos do jornal, Ilustrada e Celebridades, respectivamente. Depois disso, a menção irônica ao "travesti de dois metros" com que a popstar dança nos shows realizados em São Paulo - para o desespero dos pais ouvidos: "Eu sabia que ela dançava e usava biquíni, mas assim não dá", assume um suposto entrevistado (FELITTI, 2014a). Tais enunciados não-sérios, de acordo com a teoria dos performativos de Austin (1990), são condições de infelicidade para atos performativos, justamente porque são "parasitários” em relação ao uso ordinário da linguagem. Não caberia, então, levantar um questionamento sobre as estratégias enunciativas da Folha, que insistem em deslocar os discursos sobre trans para a ordem do “estiolamento”? ${ }^{12}$

Os enunciados irônico-morais, devidamente restritos ao entretenimento, reaparecem. Em outro texto de Felitti (2014b), na coluna Humanos (!), o leitor pode desfrutar do riso provocado pelas práticas trans do cinema pornô nacional: “[...] outros representantes, como ‘Senhor do Anel’ e 'Brincando de Boneca’ ficaram de fora: o Prêmio da Indústria Pornô, que vai laurear a nata da produção cinematográfica erótica do país, cancelou as categorias Melhor Filme Gay e Melhor Filme Transexual.” Já em 26 agosto de 2014, na coluna Factoites (humorística, também do F5), Aran (2014) cria um rol de candidatos risíveis das eleições daquele ano: bipolares, celebridades de reality shows, corruptos e “Talyta Travesti. Pela regulamentação do aborto entre casais do mesmo sexo. Curso de inglês gratuito para crossdressers, drag queens e drag kings que não sabem o que é crossdressers, drag queens e drag kings”.

Os discursos da ordem do entretenimento aparecem, ainda, em outro texto. Assim, no dia 12 de agosto de 2014, um outro espaço restrito da Folha, a coluna Estranho, traz a seguinte manchete Facebook dá mais de 50 opções de gênero sexual a usuários na Argentina. O artigo, desta feita assinado por Márcia Carmo, da BBC Brasil, expõe as

\footnotetext{
12 Ao que parece, diferente do que solicita Butler (2015; 2002), não se trata de citacionalidade, mas de um uso normatizador dos performativos, segundo os efeitos da "infelicidade".
} 
diversidades de gênero oferecidas pelo Facebook na Argentina, justifica a iniciativa com a histórica luta por inclusão e representatividade que o país manifesta. Note-se, no entanto, que o uso do autor institucional aqui tem outro efeito, marcando os limites discursivos entre a posição da Folha e a posição da BBC (CARMO, 2014). No que cabe à Folha, o título "gênero sexual” apenas retoma uma categorização problemática, em que o biológico e o cultural parecem operar dualmente - como já criticavam Nicholson ou Butler. Quanto à coluna do jornal, novamente estaremos lançados nos discursos da anormalidade, caros a Foucault (2010): Estranho é o locus de produção de textos acerca da monstruosidade, da alteridade radical, no interior da normalização escolarizada e androcêntrica dos enunciados do jornal.

Novamente, estamos diante daquilo que Jesus (2016, p. 196) chamou de "racismo institucional”, materializado no dispositivo midiático. Trata-se de um dispositivo que coloca em xeque a humanidade de certas categorias de sujeito e que, no caso das sexualidades e dos gêneros, pauta-se, como se viu anteriormente, na naturalização biomédica do binarismo e na exclusão de qualquer prática. $\mathrm{O}$ produto dessa materialização é, como se sabe, a manutenção da perda de direitos e o sequestro dos sujeitos em formas de vida mais ou menos dignas - no caso das pessoas trans, ainda sem o devido “reconhecimento”, não obstante os enunciados pretensamente liberalizantes da Folha.

Assim como o que acontece com os discursos do entretenimento, no campo das estratégias de positivação dos direitos individuais, cuja formulação indicaria a vinculação à FD Liberalizante, a Folha também logra produzir um discurso cindido. É importante frisar, no entanto, que o debate sobre os direitos das minorias estava em pauta e funcionava na modalidade de condição de produção desses discursos. O embate se dava entre um discurso progressista e um discurso arcaizante que se materializavam no debate eleitoral. Na figura de Marina Silva, de modo mais enfático, a Folha buscava recriar uma tensão entre enunciados de vanguarda e um retorno aos princípios de um discurso neopentecostal, imputado à então candidata: “A primeira versão do programa chegou a surpreender setores ligados à militância LGBT. Marina é evangélica, devota da Assembleia de Deus e disse, em 2010, ser pessoalmente "não favorável" ao casamento gay [...]” (MARQUES, 2014, [n.p.]). 
Em 29 de agosto de 2014, a sessão Poder, central no jornal sobretudo no período de eleições majoritárias, descreve o Programa e os direitos: reconhecimento da identidade de gênero, casamento civil igualitário, agilização de projeto que equipara a discriminação feita ao público LGBT com outros de vulnerabilidade social previstos no projeto 122/06, adoção para casais homoafetivos, inserção da discussão nos planos de ensino como forma de combate à violência escolar e exclusão social (o que será relido na Folha como o KIT gay). A matéria compara o plano de ensino da então candidata com os demais candidatos do mesmo período eleitoral, ressaltando que Marina é a candidata que maior ênfase dá à questão (MARQUES, 2014).

A luta discursiva da campanha de Marina Silva, dicotomizada, ganhou espaço no noticiário sobretudo pela rapidez com que o progressismo foi substituído de seu Programa de Governo (menos de 24 horas, entre 29 e 30 de agosto de 2014): “A campanha de Marina Silva (PSB) à Presidência divulgou nota neste sábado (30) retirando o apoio a propostas para a comunidade LGBT (lésbicas, gays, bissexuais, travestis, transgêneros e transexuais) citadas no programa de governo da candidata, divulgado na sexta-feira (29).” (MARQUES, 2014, [n.p.]). A Folha parte dessa conjuntura para traçar estratégias de dizer sobre o trans, que surgem na forma de epifenômeno do debate central, a saber: os direitos dos homossexuais e o "problema” da união homoafetiva, marcados e retirados do Programa de Governo de Marina Silva. Todavia, os enunciados do jornal jamais discorrem sobre o debate acerca dos direitos das pessoas trans, senão de forma esquemática e a partir da ontologização das identidades, sob a égide dos discursos sobre o “transexual verdadeiro" - a ser esquadrinhado, diagnosticado e capturado pelo dispositivo médico-jurídico.

Ao nos debruçarmos sobre os textos, é possível estabelecer que o funcionamento discursivo é o de produção e de manutenção da díade liberalizante vs. arcaizante, que percorre o discurso eleitoral da Folha em 2014. Dessa perspectiva, no texto UFSCAR dá aval a uso de 'nome social' para travesti, publicado em 19 de setembro de 2014, essa dubiedade aparece de forma tímida, mas incontornável. Inicialmente, faça-se notar que o texto não se restringe às práticas de travestismo, mas também ao que chama de “transexuais”. A Folha, entretanto, não só opera dando ênfase ao caricatural do gênero (o travestismo como experiência cuja memória brasileira pode evocar de modo estigmatizante) como não se dedica a discutir os conceitos com que opera. Observe-se, 
ainda, que o texto aparece num caderno regional, Ribeirão Preto. A matéria não é assinada por um autor, mas creditada ao próprio jornal, criando um efeito de objetividade e impessoalidade ao utilizar a ordem da “autoria institucional”, “[...] assumida internamente pela própria empresa e pelo veículo de comunicação onde é publicado” (ALVES FILHO, 2006, p. 83).

Pontual e breve, no entanto, o texto traz um discurso relatado que produz alguns efeitos importantes: a voz do vice-reitor, que suscita uma demanda de alunos para a “normatização” e exime a instituição da iniciativa inicial e, além disso, produz uma generalização do debate sobre o gênero, segundo a ordem de uma diversidade: “A UFSCar tem a tradição de trabalhar com as diferenças” (UFSCAR dá aval a uso de 'nome social' para travesti, 19/09/2014). Diante da voz da autoridade da instituição, da modalidade de enunciação legítima, porém, não há qualquer opção de heterogeneidade enunciativa e não se relata nenhuma espécie de ponto de vista - sobretudo a partir das vozes que ali são descritas, das pessoas trans.

Por fim, e não menos importante, o texto revela uma espécie de voluntarismo na descrição do "nome social”: “adotado pela pessoa e que não consta em seus documentos oficiais”. A Folha está bastante distante de uma postura de resistência ou de discussão, não obstante sua insistência liberalizante. Como aponta Bento (2014, p. 175), o "nome social” figura, no Brasil, como uma gambiarra, que acaba definindo modos de ser cidadão bastante distintos, a partir da “normalidade” sexual-genérica:

O Brasil é o único país do mundo onde, no vácuo de uma legislação geral, instituições garantem um direito negado globalmente. Aqui transmutamos o respeito à identidade de gênero em "nome social”. [...] Mudar sem alterar substancialmente nada na vida da população mais excluída da cidadania nacional.

Bento (2014) aponta que a estratégia micro-política do nome social passa por um dispositivo médico-jurídico que captura os sujeitos trans segundo critérios patológicos, sem oferecer garantias de cidadania efetiva - o que só ocorre mediante decisões judiciais. No dispositivo jornalístico da Folha, trata-se de um jogo de repetição de enunciados sobre a cidadania, devidamente deslocados e não problematizados. A única contraposição possível (no caso, a solicitação de uso de nomes sociais) é tratada como iniciativa particular, individual, fora-do-comum (o texto se conclui afirmando que "ainda 
não há registros de quantas pessoas têm interesse em usar o nome social”).

Essa ausência também pode ser formulada em relação à memória dos enunciados. Conforme Foucault (2012, p. 68-69), o campo enunciativo é um regime de coexistência, composto de um campo de presença (próximo às condições de veridicção e validação, da polêmica e da transformação referentes ao mesmo de um saber), um campo de concomitância (os enunciados que pertencem a domínios distintos, mas que determinam a construção de enunciados de um campo) e, finalmente, um campo de memória, que pode não ser admitido nem definir domínios de validade, mas “[...] em relação aos quais se estabelecem laços de filiação, gênese, transformação, continuidade e descontinuidade histórica”. No que tange à memória, aproximemos a Arqueologia de $A$ Ordem do Discurso e seus procedimentos de exclusão. Foucault (2002) mostra que o mais familiar desses procedimentos é a interdição, promotor de uma luta discursiva pelo dizer. Para o francês, sexualidade e política teriam privilégio entre os discursos interditados.

Do binômio memória e exclusão, podemos inferir que a circulação dos discursos, conforme a arqueogenealogia, obedece, além de uma produção e de uma ubiquidade, a alguns procedimentos de silenciamento. Voltando à Folha, como se disse anteriormente, a produção de discursos sobre as práticas trans é bastante restrita. Some-se a isso o fato de que a voz trans é reduzida, interditada, silenciada: epifenômeno interditado. É, em geral, a partir de uma rede de saberes médico-legais de normalização ou segundo a ordem do entretenimento e do risível que surgem as práticas trans. De outro modo, elas aparecem como mote de cisão discursiva, de disjunção - como no caso de Marina da Silva. No interior do dispositivo transexual materializado na Folha, os discursos permanecem como prerrogativa médico-jurídica e, portanto, indicam a ausência da voz das pessoas trans e de sua resistência. Os enunciados não fazem menção a qualquer alternativa de despatologização - como a discussão atual da Organização Mundial de Saúde e do ativismo trans (TENÓRIO; PRADO, 2016) - mas retomam seletivamente enunciados de injunção à normalização binária heteronormativa.

O solo discursivo de onde partem os discursos da Folha é o mesmo de que trata Vieira (2015), quando a autora produz uma narrativa histórica do tratamento dado às transexuais no período da 'linha dura', elencando manchetes do período histórico referido apontando por uma caça às pessoas trans por parte da polícia. Como estratégia de luta, muitas se cortavam expondo seu sangue que era tido como "venenoso" por uma 
biopolítica que as enquadrava como proliferadoras de HIV. Na ordem do interdito, Vieira (2015) nota que em jornais, revistas ou livros não havia nenhuma menção à segregação. A invisibilidade, portanto, não se tornava memória de sofrimento ou de luta. Os discursos sobre trans da Folha, como se pode notar nas breves análises aqui realizadas, ainda figuram como uma espécie de abjeção fantasmática, cuja materialização escapa ao dizer normal de um dispositivo sexual-midiático binário e heteronormativo, cindido entre uma estratégia liberalizante e uma tática ubíqua de normalização - moral, religiosa, política produzida pelo dispositivo transexual no Brasil.

\section{Considerações finais}

Este texto teve como objetivo observar o funcionamento discursivo da Folha de São Paulo no que se refere à produção de discursos sobre/de trans, tomado como ponto de inflexão do dispositivo transexual, por um lado, e vértice de normalização e exclusão, de outro.

A leitura discursiva da Folha fez notar estratégias de dizer ainda pautadas na normalização ou na espetacularização dos discursos, não obstante o esforço de submeter os textos a efeitos de progressismo e liberalidade. Outrossim, o que se nota é um forte silenciamento dos dizeres trans, excluídos das séries de memória dos discursos, mantidos na ordem do pastiche e da tradução - em termos do binarismo heteronormativo ou da injunção pela psiquiatrização.

Por fim, cabe fazer uma ressalva, axial: não obstante o caráter disjuntivo da discussão trans hodierna, em termos de resistência diante do dispositivo biopolítico de objetificação e subjetivação, o embate agonístico entre resistência e poder materializado na Folha ainda aponta para a capacidade plástica e normativa do dispositivo da transexualidade, conforme pensado por Foucault. As resistências, em várias modalidades e níveis, ainda aparecem de forma tímida quando tomadas por um conjunto organizado de práticas discursivas, como a jornalística, que obedece a urgências históricas específicas. Tal implicação entre o dispositivo jornalístico e a ratificação da exclusão é, pois, o limite sobre o qual outras pesquisas deverão se voltar, a fim de inventariar uma ontologia, crítica, de nós mesmos e de nossos desejos fora-da-norma. 
BUTTURI JUNIOR, Atilio; D’ÁVILA, Denise Ayres. The Journalistic Apparatus and Trans Discourses: an analysis of Folha de São Paulo. Revista do Gel, v. 14, n. 1, p. 242252, 2017.

Abstract: This paper aims to problematize the production of discourses about transgender people in Brazilian media, from an analysis of the foucaultian debates and some gender and transfeminism today's discussions. The corpus consists of online texts (published between August 1, 2014 and October 3, 2014), at the daily edition of the newspaper Folha de São Paulo that deal, in different ways, with aspects of trans discourses. The hypothesis to be defended is that, despite the shifts undertaken by gender discourses and the transfeminism, remain in Folhas's discourse statements of normalization and naturalization in the production of texts on the trans event.

Keywords: Trans. Apparatus. Discourse. Media. Gender production.

Submetido em: 30/05/2016.

Aceito em: 23/01/2017.

\section{Referências}

AGAMBEN, G. O amigo. O que é um dispositivo. Tradução de Vinícius Nicastro Honesko. Chapecó: Argos, 2014.

ALVES FILHO, F. A autoria institucional nos editoriais de jornais. Alfa, São Paulo, v. 50, n. 1, p. 77-89, 2006.

ARAN, E. Humor: Não sabe em quem votar? Escolha o seu candidato a deputado federal. Folha de São Paulo, São Paulo, 26 ago. 2014. F5. Disponível em: $<$ http://f5.folha.uol.com.br/factoides/2014/08/1505393-humor-nao-sabe-em-quemvotar-escolha-o-seu-candidato-a-deputado-federal.shtml>. Acesso em: 10 abr. 2017.

AUSTIN, J. L. Quando dizer é fazer. Tradução de Danilo Marcondes de Souza Filho. Porto Alegre: Artes Médicas, 1990.

ARÁN, M.; MURTA, D.; LIONÇO, T. Transexualidade e saúde pública no Brasil. Ciência \& Saúde Coletiva, v. 14, p. 1141-1149, 2009.

BENTO, B. A reinvenção do corpo: sexualidade e gênero na experiência transexual. Rio de Janeiro: Garamond, 2006. A diferença que faz a diferença: corpo e subjetividade na transexualidade.

Bagoas, Natal, v. 3, n. 4, p. 95-112, 2012. Disponível em:

<https://periodicos.ufrn.br/bagoas/article/view/2298/1731>. Acesso em: 10 mai. 2013. 
Nome social para pessoas trans: cidadania precária e gambiarra legal.

Contemporânea, v. 4, n. 1, p. 165-182, jan.-jul. 2014. Disponível em:

$<$ http://www.contemporanea.ufscar.br/index.php/contemporanea/article/viewFile/197/101>.

Acesso em: 14 jul. 2015.

BENTO, B.; PELÚCIO, L. Despatologização do gênero: a politização das identidades abjetas. Estudos Feministas, Florianópolis, v. 20, n. 2, p. 569-581, mai.-ago. 2012.

BORBA, R. (Des)aprendendo a "ser": trajetórias de socialização e performances narrativas no processo transexualizador. 2014. 205 f. Tese (Doutorado) - Faculdade de Letras, Universidade Federal do Rio de Janeiro, Rio de Janeiro, 2014a.

. Sobre os obstáculos discursivos para a atenção integral e humanizada à saúde de pessoas transexuais. Sexualidad, Salud y Sociedad, v. 17, p. 66-97, 2014b.

BUTLER, J. Cuerpos qui importan. Buenos Aires: Paidós, 2002.

Undiagnosing gender. In: . Undoing gender. New York: Routledge, 2004. p. 74-101.

Doing justice to someone. In: STRYQUER, S.; WHITLLE, S. (Ed.). The transgender studies reader. New York: Routledge, 2006. p. 183-193.

Problemas de gênero: feminismo e subversão da identidade. Tradução de Renato Aguiar. Rio de Janeiro: Ed. Civilização Brasileira, 2015.

BUTTURI JUNIOR, A. A passividade e o fantasma: o discurso monossexual no Brasil. 2012. 280 f. Tese (Doutorado em Linguística) - Programa de Pós-graduação em Linguística, Universidade Federal de Santa Catarina, Florianópolis, 2012.

. A autoria, o dispositivo e a ética: os limites da (des)subjetivação na escrita.

Alfa, São Paulo, v. 60, n. 3, p.5 07-530, 2016. Disponível em:

$<$ http://www.scielo.br/scielo.php?script=sci_arttext\&pid=S1981-

57942016000300507\&lng=pt\&nrm=iso\&tlng=pt> . Acesso em: 10 jan. 2017.

CARMO, M. Facebook dá mais de 50 opções de gênero sexual a usuários na Argentina.

Folha de São Paulo, São Paulo, 12 ago. 2014. BBC Brasil.

COUTINHO, L. Crítica: Série 'Transparent' humaniza a questão de gênero. Folha de São Paulo, São Paulo, 26 set. 2014. Disponível em:

$<$ http://www1.folha.uol.com.br/ilustrada/2014/09/1522408-critica-serie-transparenthumaniza-a-questao-de-genero.shtml>. Acesso em: 15 jun. 2015.

DELEUZE, G. Foucault. Tradução de Claudia Sant’Anna Martins. São Paulo:

Brasiliense, 2005.

DSM-V. Manual diagnóstico e estatístico de transtornos mentais. Tradução de Maria Inês Corrêa Nascimento et al. 5. ed. rev. Porto Alegre: Artmed, 2014. 
ENKE, A. F. The education of little cis. In: ENKE, A. Transfeminism perspectives. Philadelphia: Temple University Press, 2012. p. 60-80.

FELITTI, C. Pais só aguentam três músicas em show de Miley Cyrus. Folha de São Paulo, São Paulo, 26 set. 2014a. F5. Disponível em:

$<$ http://f5.folha.uol.com.br/celebridades/2014/09/1523498-pais-deixam-show-de-mileycyrus-antes-da-quarta-musica.shtml>. Acesso em: 10 abr. 2017.

. 'Oscar' do pornô não terá categorias gay e trans por falta de inscritos. Folha de São Paulo, São Paulo, 3 out. 2014b. F5. Disponível em: $<$ http://f5.folha.uol.com.br/humanos/2014/10/1526579-oscar-do-porno-nao-teracategorias-gay-e-trans-por-falta-de-inscritos.shtml>. Acesso em: 10 abr. 2017.

FELTRIN, R. Cachê comercial de Fátima Bernardes dispara. Folha de São Paulo, São Paulo, 25 set. 2014b. F5. Disponível em:

<http://f5.folha.uol.com.br/colunistas/ricardofeltrin/2014/09/1522289-cache-comercialde-fatima-bernardes-dispara.shtml>. Acesso em: 10 abr. 2017.

FOLHA DE SÃO PAULO. História da folha/Perfil do leitor. Disponível em: $<$ http://www1.folha.uol.com.br/folha/circulo/historia_2000.htm>. Acesso em: 20 mar. 2016.

FOUCAULT, M. Vigiar e punir: nascimento da prisão. Tradução de Raquel Ramalhete. Petrópolis: Vozes, 1987.

Os anormais: curso no Collège de France (1974-1975). Tradução de Eduardo Brandão. São Paulo: Martins Fontes, 2001.

A ordem do discurso: aula inaugural no Collège de France, pronunciada em 02 de dezembro de 1970. 8. ed. Tradução de Laura Fraga de Almeida Sampaio. São Paulo: Loyola, 2002.

História da sexualidade I: a vontade de saber. Tradução de Maria Tereza de Albuquerque e J. A. Guilhon Albuquerque. Rio de Janeiro: Graal, 2009a.

Não ao sexo rei. In: . Microfísica do poder. 11. ed. Tradução de Roberto Machado. Rio de Janeiro: Graal, 2009b. p. 229-242.

Em defesa da sociedade - curso no Collège de France, 1975-1976. Tradução de Maria Ermantina Galvão. 2. ed. São Paulo: Martins Fontes, 2010.

A arqueologia do saber. 8. ed. Tradução de Luiz Felipe Baeta Neves. Rio de Janeiro: Forense Universitária, 2012.

JESUS, J. G. Medicina: uma ciência maligna? Debate psicopolítico sobre estereótipos e fatos. Periódicus, v. 1, n. 5 p. 195-204, mai.-out. 2016.

JESUS, J. G.; ALVES, H. Feminismo transgênero e movimentos de mulheres 
transexuais. Chronos, Natal, v. 11, n. 2, 2012.

LAQUEUR, T. Inventando o sexo: corpo e gênero dos gregos a Freud. Tradução de Vera Whately. Rio de Janeiro: Relumé Dumará, 2001.

LEITE JR., J. Nossos corpos também mudam: a invenção das categorias “travesti” e “transexual” no discurso científico. São Paulo: Annablume, 2011.

MARQUES, J. Marina recua sobre apoio a lei favorável ao casamento gay. Folha de São Paulo, São Paulo, 31 ago. 2014. F5. Disponível em:

$<$ http://www1.folha.uol.com.br/fsp/poder/183295-marina-recua-sobre-apoio-a-lei-

favoravel-ao-casamento-gay.shtml>. Acesso em: 10 abr. 2017.

MOTA, V. Tudo sobre a Folha. 2000. Disponível em:

$<$ http://www1.folha.uol.com.br/folha/80anos/quem_e_o_leitor.shtml>. Acesso em: 20 mar. 2016.

NICHOLSON, L. Interpretando o gênero. Estudos Feministas, Florianópolis, v. 8, n. 2, p. 9, jan. 2000. Disponível em:

< https://periodicos.ufsc.br/index.php/ref/article/view/11917>. Acesso em: 11 mai. 2015.

PRECIADO, B. Manifiesto contra-sexual. Madrid: Editorial Opera Prima, 2002.

SENRA, R. Transposição: Diversidade. Folha de São Paulo, São Paulo, Revista São Paulo, p. 18-22, 9 mar. 2014.

PROSSER, J. Judith Butler: queer feminism, transgender and the transubstantiation of sex. In: STRYQUER, S.; WHITLLE, S. (Ed.). The transgender studies reader. New York: Routledge, 2006. p. 257-280.

STRYQUER, S. Transgender history. Berkeley: Seal Press. 2008.

TENÓRIO, L. F. P.; PRADO, M. A. M. As contradições da patologização das identidades trans e argumentos para a mudança de paradigma. Periódicus, Natal, v. 1, n. 5, p. 41-55, mai.-out. 2016.

VIEIRA, H. Onde estavam os travestis na ditadura? Fórum, São Paulo, 05 de abr. de 2015. Os entendidos. Disponível em:

$<$ http://www.revistaforum.com.br/osentendidos/2015/04/05/onde-estavam-travestisdurante-ditadura/>. Acesso em: 08 nov. 2015. 